\title{
Inhalt.
}

\section{Stereometrie. Verzeichnisse.}

Stereometrie $3-54$

4. Geschichtlicher Überblick. . . . . . . . . . . . . . . 3- 8

B. Besonderer Teil . . . . . . . . . . . . . . . . . . 9-54

1. Die geraden Linien und die Ebenen im Raum . . . . 9- 14

2. Die Volumen- und Oberflächenberechnungen. . . . . . 14- 54

a) Allgemeines . . . . . . . . . . . . . . . . . . . . . . . . . . . 14-16

b) Parallelepipedon und Prisma. . . . . . . . . . . 16- 20

c) Die Pyramide . . . . . . . . . . . . . . . . . . . . . . . . . . . . $20-29$

d) Zylinder und Kegel . . . . . . . . . . . . . . 29-34

e) Die Kugel und die allgemeinen Rotationskörper . . . 35- 42

f) Allgemeine Körper. Das Cavaligra sche Prinzip. Die Srmpson sche Regel . . . . . . . . . . . . . 42- 54

Verzeichnis I: Namen und Schriften . . . . . . . . . 55-100

Verzeichnis II: Sachliches . . . . . . . . . . . . . . 101-128 
